\title{
Microstructural Characteristics of Diecast AlMgSiMn Alloy Shouxun $\mathrm{Ji}^{1,}$ a , Yun Wang ${ }^{1}$, Douglas Watson ${ }^{1,2}$ and Zhongyun Fan ${ }^{1, b}$

\author{
${ }^{1}$ Brunel Centre for Advanced Solidification Technology (BCAST), Brunel University, Uxbridge UB8
} $3 \mathrm{PH}$, United Kingdom \\ 2Jaguar Cars Limited, Engineering Centre, Abbey Road, Coventry, CV3 4LF, United Kingdom \\ ashouxun.j@@brunel.ac.uk, bzhongyun.fan@brunel.ac.uk
}

\begin{abstract}
Keywords: Solidification; microstructural evolution; die casting; Al-Mg-Si-Mn alloy
\end{abstract}
\begin{abstract}
Solidification and microstructural characteristics of Al-5wt.\%Mg-1.5wt.\%Si-0.6wt.\%Mn$0.2 \mathrm{wt} . \% \mathrm{Ti}$ alloy have been investigated in high pressure die casting. The average size of dendrites and fragmented dendrites of the primary $\alpha$-Al phase formed in the shot sleeve is $43 \mu \mathrm{m}$, and the globular $\alpha$-Al grains formed inside the die cavity is $7.5 \mu \mathrm{m}$. Solidification inside the die cavity also forms the lamellar Al- $\mathrm{Mg}_{2} \mathrm{Si}$ eutectic phase and the Fe-rich intermetallics. The size of the eutectic cells is about $10 \mu \mathrm{m}$, in which the lamellar $\alpha$-Al phase is $0.41 \mu \mathrm{m}$ thick. The Fe-rich intermetallic compound exhibits a compact morphology and is less than $2 \mu \mathrm{m}$. Calculations using the Mullins and Sekerka stability criterion reveal that the solidification of the primary $\alpha$-Al phase inside the die cavity has completed before the spherical $\alpha$-Al globules begin to lose their stability, but the $\alpha$-Al grains formed in the shot sleeve exceed the limit of spherical growth and therefore exhibit a dendritic morphology.
\end{abstract}

\section{Introduction}

High pressure die casting (HPDC) is a common process used in casting industry. The attractiveness of HPDC is its ability to make near net-shape parts with tight tolerances $[1,2]$. HPDC is often used to make components for non-structural applications. However, they are attracting increased interest in the products of structural applications, particularly in transportation such as automotive markets because of the driving force in weight savings for improved fuel economy $[3,4]$. One of the significant developments in recent years has been their application in aluminium car body structures [5,6]. Unique mechanical properties such as high ductility are required for this specific application. To achieve the requirement, several critical aspects need to be precisely controlled during manufacturing which include an optimized alloy composition, low level of gas content and impurities in melt prior to solidification, minimized defect level and an optimised microstructure in castings.

Al-Mg-Si based alloys are capable of providing high ductility and an excellent combination of mechanical properties for die castings in the as-cast state [7,8]. However, the diecast Al-Mg-Si based alloys are known to have high solidification shrinkage which, therefore, increases the difficulty of producing castings with high integrity $[9,10]$. As such, the microstructural evolution and the related control during solidification are becoming very important for achieving enhanced mechanical properties of the Al-Mg-Si alloy.

In this work, the solidification behaviour in the shot sleeve and in the die cavity was examined for the formation of the primary $\alpha$-Al phase, eutectic phase and Fe-rich intermetallics in Al5wt.\%Mg-1.5wt.\%Si-0.6wt.\%Mn-0.2wt.\%Ti (abbreviated as AlMgSiMn hereafter) alloy. The growth morphology of the primary $\alpha$-Al phase formed in the shot sleeve and in the die cavity was analysed using the Mullins-Sekerka instability theory.

\section{Experimental}

Commercial grade ingots of pure aluminium, pure magnesium, Al-15wt.\%Si, Al-20wt.\%Mn, and Al-10wt.\%Ti master alloys were used to make target alloy. Batches of 6 to $10 \mathrm{~kg}$ were melted in a 
clay-graphite crucible using an electric resistance furnace at $730^{\circ} \mathrm{C}$. For all the experiments, the melt was subjected to fluxing and degassing using commercially available fluxes and $\mathrm{N}_{2}$ for 3 minutes. Then the melt was held at $700^{\circ} \mathrm{C}$ for 20 minutes before taking a sample for composition measurement using a $\phi 40 \times 60 \mathrm{~mm}$ cylindrical casting. The cylindrical casting was cut across the diameter at $15 \mathrm{~mm}$ from the bottom. The composition measurements were conducted with an optical mass spectrometer, in which five spark analyses were performed and the average value was taken as the actual chemical composition of the alloy.

After composition analysis and skimming, the melt was manually dosed and subsequently released into the shot sleeve of a $2800 \mathrm{kN}$ cold chamber HPDC machine for casting under an optimized casting condition. The temperature of the die block was controlled at $210^{\circ} \mathrm{C}$ and the temperature of shot sleeve was controlled at $150^{\circ} \mathrm{C}$ during casting. The pouring temperature of the melt was $650 \pm 5^{\circ} \mathrm{C}$ measured by a K-type thermocouple. Four samples designed according to the specification defined in ASTM B557-06 for tensile tests were made in each shot.

The samples for microstructural characterization were taken from the middle of the tensile test bar, and examined using a Zeiss optical microscope (OM) with quantitative metallography and a field emission gun Zeiss SUPRA 35VP Scanning electron microscopy (SEM) equipped with an energy dispersive spectroscopy (EDS) facility and operated at an accelerating voltage of 3-20KV.

\section{Results}

Figure 1 shows the microstructures of a tensile specimen in the die-cast AlMgSiMn alloy. It shows a solute enriched band that is parallel to the skin of the casting (Fig. 1a). The similar phenomenon of band formation has been observed and analysed by Dahle et al. for different alloys [11]. Two types of primary $\alpha-\mathrm{Al}$ phases are seen in the microstructure shown in Figure 1. The
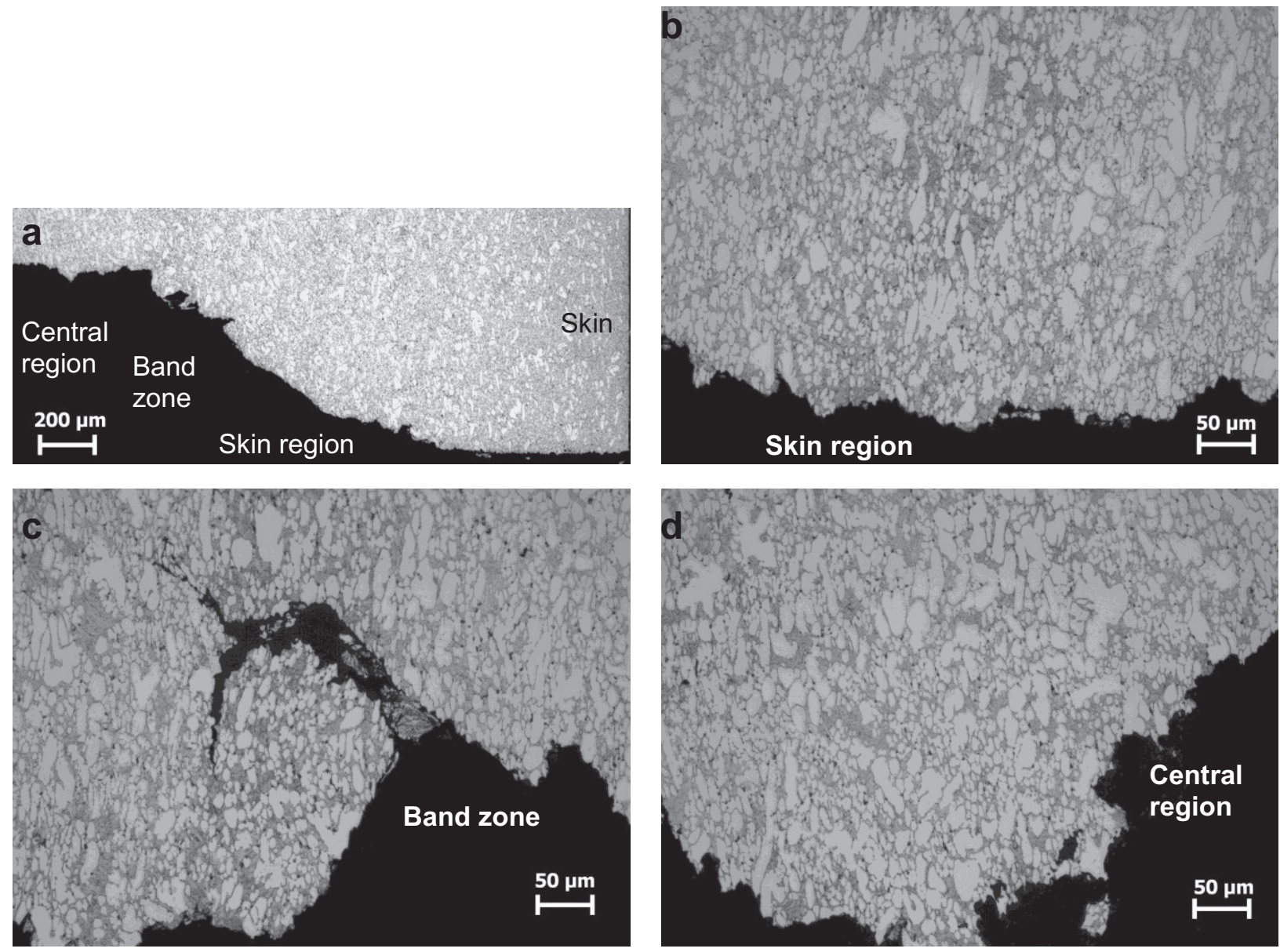

Fig. 1. Optical micrographs showing the microstructure on a section perpendicular to the fractured surface of the AlMgSiMn alloy, (a) over all microstructure, (b) the skin region, (c) the band zone, and (d) the central region. 
primary $\alpha-\mathrm{Al}$ phase that solidifies in the shot sleeve exhibits a relatively large size with dendritic or fragmented dendritic morphology. The primary $\alpha$-Al phase that solidifies in the die cavity shows a relatively smaller size with a globular morphology. A higher volume fraction of the primary $\alpha$-Al phase that solidifies in the shot sleeve is observed in the central region compared to that in the outer skin region of the casting (Fig. 1b,c\&d). In the transition band zone, the volume fraction of eutectic phase is higher compared to that in both the skin and the central region.

The composition analysis showed a variation in magnesium and silicon concentration from the surface to the center of the AlMgSiMn casting. The concentrations are consistent in the skin region with a general drop toward to the center inside the band. For instance, the $\mathrm{Mg}$ concentration is close to the nominal composition of $5 \mathrm{wt} . \%$ in the skin region and gradually decreases to $3.8 \mathrm{wt} . \%$ at the centre of the casting, whilst the Si concentration is also close to its nominal composition at $1.5 \mathrm{wt} . \%$ in the skin region but slightly lower in the central region. The band zone is found to be enriched in $\mathrm{Mg}$ and Si to $8.8 \mathrm{wt} . \%$ and $2.9 \mathrm{wt} . \%$, respectively. The peak of the solute enrichment in the band zone is much higher than the nominal composition in the alloy. Therefore the segregation of the solute distribution on the cross section of the die castings is an essential phenomenon. The formation of central core is related to the solidification conditions in HPDC process because the solidification occurs during relative movement of melt at different parts in the die cavity.

In Figure 1, it is also seen the microstructure along the fractured surface in the skin region, band zone and central region. The primary $\alpha-\mathrm{Al}$ grains are slightly stretched towards the fractured surface. The micrographs confirm that the fracture occurs mainly along the $\alpha-\mathrm{Al}$ grain boundaries, and the fracture across the primary $\alpha-\mathrm{Al}$ grains is also found in the skin region, band zone and central region. Meanwhile, a few subsurface pores in irregular shapes are observed close to the fractured surface in the band zone and the central region. This suggests that the cracking as the fracture source is likely initiated in the band zone and the central region under stress. Therefore, although the solute-rich segregation is observed in the band zone, it is not significantly detrimental in terms of the fracture mechanism in the die-cast AlMgSiMn alloy.

In high pressure die casting, the solidification commences when the melt is poured into the shot sleeve. Because the cooling rate inside the shot sleeve is similar to that in gravity die casting, a cooling rate in the range of $20-80 \mathrm{~K} / \mathrm{s}$ could be achieved [12], the solidification initiates from the nucleation of the $\alpha$-Al crystals that subsequently grow dendritically in the shot sleeve. The primary $\alpha$-Al dendrites are fragmented when the melt is injected into the die cavity through the ingate at a high speed, resulting in the formation of fragmented dendrites in the microstructure. Figures $2 \mathrm{a}$ shows the typical primary $\alpha$-Al crystals solidified in the shot sleeve and in the die cavity. The size distribution of the primary $\alpha-\mathrm{Al}$ phase is between 15 and $100 \mu \mathrm{m}$ with a mean of $43 \mu \mathrm{m}$ (Fig. $3 \mathrm{a}$ ). The distribution of the primary $\alpha$-Al phase shows a very close match to a Gaussian distribution. When the melt is injected into the die cavity, the remnant liquid in the mixture that contain primary $\alpha$-Al phase starts to solidify immediately. As the solidification inside the die cavity occurs under a high cooling rate, which is typically in the range of $400-500 \mathrm{~K} / \mathrm{s}$ [12], the high cooling rate increases the nucleation rate and thus exhibits different morphology. In Fig. 2a, it is also seen the primary $\alpha$-Al crystals formed in the die cavity. The grain size is between 3 and $12 \mu \mathrm{m}$ and the average is $7.5 \mu \mathrm{m}$ (Fig. 3b). The distribution curve also matches a Gaussian distribution with a mean of 7.5 .

The morphology of the eutectic phase is shown in Figure 2b. EDS analysis confirms that the lamellar microstructure of the eutectic consists of $\alpha-\mathrm{Al}$ phase and $\mathrm{Mg}_{2} \mathrm{Si}$ phase. The size of the eutectic cells is about $10 \mu \mathrm{m}$, in which the lamellar $\alpha$-Al phase is $0.41 \mu \mathrm{m}$ in thickness. SEM observation on a deep-etched sample reveals that the eutectic $\mathrm{Mg}_{2} \mathrm{Si}$ phase exhibits fine lamellae morphology and branching of the flakes is frequently observed. This suggests that the solidification follows a conventional path under a high cooling rate. There is no thick platelet $\mathrm{Mg}_{2} \mathrm{Si}$ phase observed in the samples. The amount of eutectic largely depends on the composition of the alloy. An increased level of $\mathrm{Mg}$ and $\mathrm{Si}$ in the alloy creates more eutectic phase, which would cause an increase in strength and a decrease in ductility. 

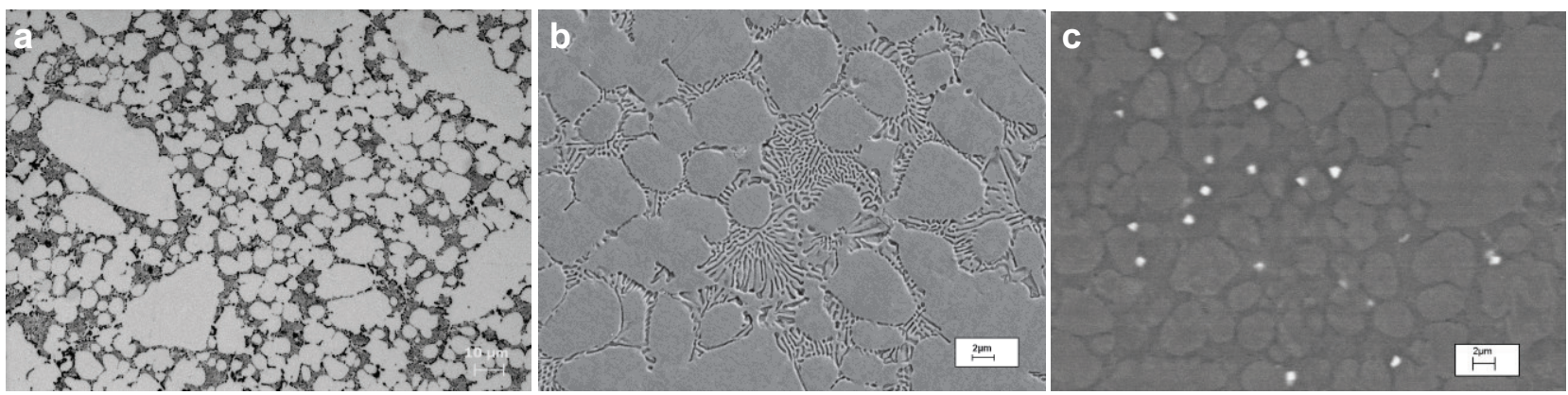

Fig. 2. Microstructures of diecast AlMgSiMn alloy (a) primary $\alpha-\mathrm{Al}$ phase formed in shot sleeve (coarse globular) and formed in die cavity (fine glubular), (b) eutectic phase, (c) intermetallics.
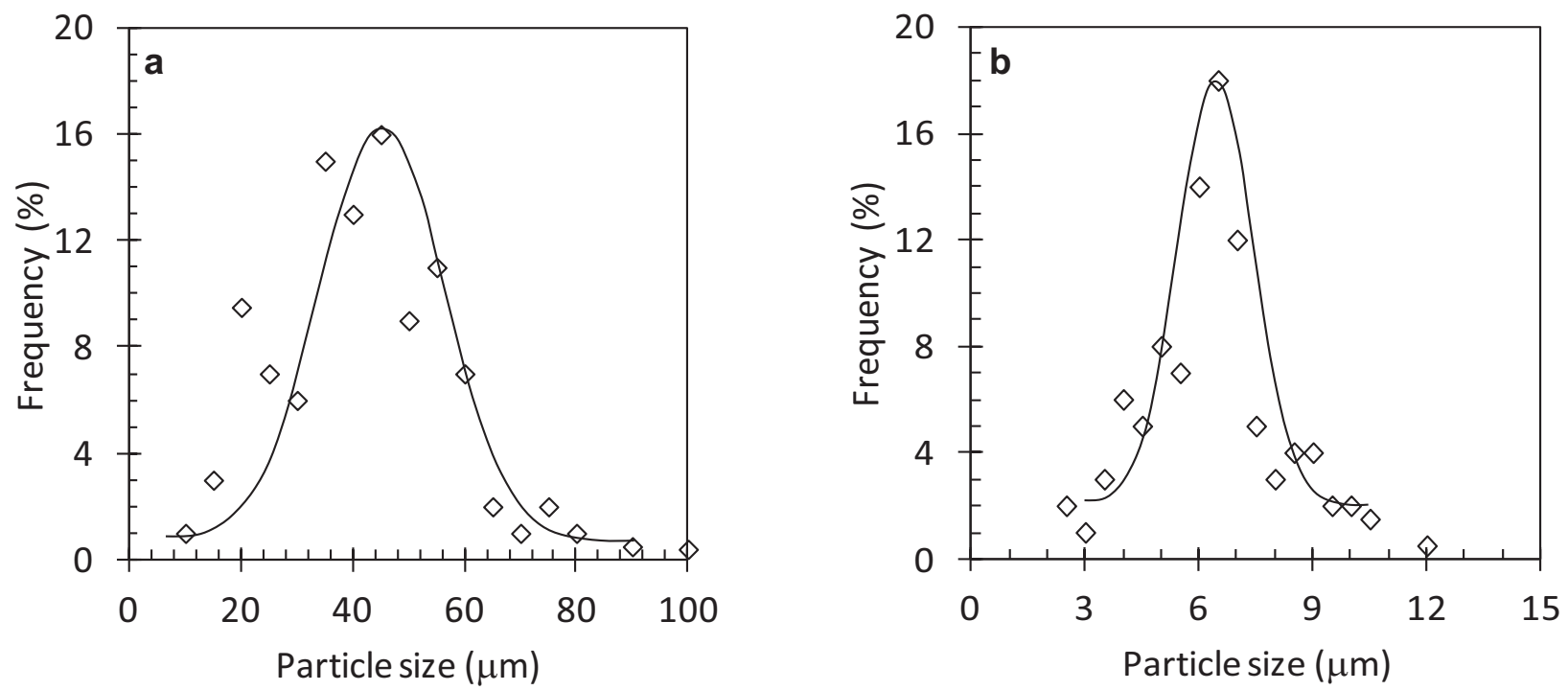

Fig. 3. The distribution of the solid $\alpha$-Al phase, (a) solidified in the shot sleeve with a Gaussian distribution with a mean of 43, (b) solidified in the die cavity with a Gaussian distribution with a mean of 7.5.

Figure 2c shows the intermetallic phase in the matrix. The intermetallics exhibit a compact morphology with the size being smaller than $2 \mu \mathrm{m}$ and are located on the boundary between the primary $\alpha-\mathrm{Al}$ grains or between the eutectic cells and the primary $\alpha$-Al grains. This suggests that the intermetallics are formed in the die cavity, rather than in the shot sleeve. The EDS analysis reveals that the compact intermetallic compounds consist of $\mathrm{Al}, \mathrm{Mn}, \mathrm{Fe}, \mathrm{Si}$ with the composition being quantified to be 1.62 at. $\% \mathrm{Si}, 3.94 \mathrm{at} . \% \mathrm{Fe}$ and $2.31 \mathrm{at} . \% \mathrm{Mn}$, most likely the $\alpha$-AlFeMnSi, rather than the $\beta$-AlFeSi phase.

\section{Discussion}

Solidification in HPDC process includes two stages, one is in shot sleeve and the other is in die cavity. Due to the different cooling rate, the primary $\alpha$-Al phase exhibits different morphology. The high turbulent flow promotes the temperature uniformity in the melt throughout the die cavity and the large metallic die block provides high cooling rate. Therefore, nucleation inside the die cavity is expected to take place throughout the entire volume of the remaining liquid. The numerous nuclei compete growing until solidification finishes under high cooling rate inside the die cavity. The fine primary $\alpha$-Al grains could be formed within spherical growth morphology because the dendritic morphology that is established through unstable growth may have not yet developed. This can be explained by applying the Mullins-Sekerka growth theory [13].

The Mullins and Sekerka growth theory calculates the point where the spherical shape of crystal growing from a melt becomes morphologically unstable when its size exceeds a critical value $R_{c}$ (in $\mu \mathrm{m})[13]$ : 


$$
R_{c}=\frac{2 \Gamma_{T}\left(7+4 k_{S} / k_{l}\right)}{\left(T_{m}-T_{\infty}\right) / T_{m}}=\frac{2\left(\gamma_{S L} / L_{v}\right)\left(7+4 k_{s} / k_{l}\right)}{\Delta T / T_{m}}
$$

where $T_{m}$ and $T_{\infty}$ are the melting point and melt temperature, $k_{s}$ and $k_{l}$ are thermal conductivity of liquid and solid $\mathrm{Al}$ at the melting point temperature, $\gamma_{S L}$ is the interfacial energy at the $\mathrm{S} / \mathrm{L}$ interface, and $L_{v}$ the latent heat of fusion per unit volume of the solid. According to this stability criterion for spherical growth in a uniformly supercooled melt, one can predict that all solid spheres undergoing thermally controlled growth are morphologically stable by substituting respective values in Table 1 [14,15] into Equation (1) giving:

$$
R_{c}=\frac{5.12}{\Delta T}
$$

It indicates that the critical radius is quite sensitive to the undercooling for spherical growth of aluminium crystal. When $\Delta \mathrm{T}=1 \mathrm{~K}$, all spherical aluminium crystals less than $10.24 \mu \mathrm{m}$ in size will be stable for spherical growth. By contrast, when $\Delta \mathrm{T}=0.1 \mathrm{~K}$, all grains smaller than $102.4 \mu \mathrm{m}$ will be spherically stable. It is obvious that a smaller undercooling will promote the formation of larger spherical crystals during solidification. Therefore, we can approximately estimate the local solidification time for the $\alpha$-Al in the AlMgSiMn alloy. As the average grain size has been measured to be $7.5 \mu \mathrm{m}$, it gives a local solidification time of about $1 \mathrm{~s}$ according to the measurement results in ref. [16]. This gives a growth rate of $3.9 \mu \mathrm{m} / \mathrm{s}$. According to Burden and Hunt [17, 18], an undercooling is expected to be $1.3 \mathrm{~K}$ at this growth rate. The Mullins-Sekerka critical value can then be calculated at $7.9 \mu \mathrm{m}$, which is close to but larger than the average size measured in this study. As a result, grain growth during solidification within the die cavity can be within the stable growth regime and form a globular microstructure.

Table 1.Thermochemical and physical properties of solid and liquid aluminium at melting point

\begin{tabular}{lcll}
\hline Name & Symbol & Unit & Value \\
\hline Melting point & $T_{m}$ & $\mathrm{~K}$ & 933.5 \\
Density of liquid aluminium at $T_{m}$ & $\rho_{L}$ & $\mathrm{~g} / \mathrm{cm}^{3}$ & 2.385 \\
Volume change from solid to liquid at $T_{m}$ & $\Delta V_{m}$ & & $6.5 \%$ \\
Density of solid aluminium at $T_{m}$ & $\rho_{S}$ & $\mathrm{~g} / \mathrm{cm}^{3}$ & $2.540^{*}$ \\
Thermal conductivity of liquid aluminium at $T_{m}$ & $k_{L}$ & $\mathrm{~W} / \mathrm{m} / \mathrm{K}$ & 94.03 \\
Thermal conductivity of solid aluminium at $T_{m}$ & $k_{S}$ & $\mathrm{~W} / \mathrm{m} / \mathrm{K}$ & $238^{* *}$ \\
Latent heat of fusion per mole of aluminium & $L_{m}$ & $\mathrm{~J} / \mathrm{mol}$ & $1.047 \times 10^{4}$ \\
Latent heat of fusion per unit volume of aluminium & $L_{v}$ & $\mathrm{~J} / \mathrm{m}^{3}$ & $9.857 \times 10^{8 * * *}$ \\
Solid-liquid interfacial free energy of aluminium at $T_{m}$ & $\gamma_{S L}$ & $\mathrm{~J} / \mathrm{m}^{2}$ & $158 \times 10^{-3}$ \\
\hline
\end{tabular}

${ }^{*}$ Calculated according to $\Delta V_{m}$ and $\rho_{L}$ at melting point $T_{m}$.

${ }^{* *}$ The value of $k_{S}$ is not available. The value given here is for $673 \mathrm{~K}$.

Calculated from $L_{m} / k_{S}$.

The results from Mullins-Sekerka growth theory can also be used to explain the formation of the dendritic $\alpha$-Al phase formed in the shot sleeve. The melt usually stays in the shot sleeve for 2 to 3 seconds from the time of pouring into the shot sleeve to the time of injection through the ingate of the casting. If it is assumed that a similar growth velocity of $3.9 \mu \mathrm{m} / \mathrm{s}$ exists for the $\alpha$-Al phase, the resultant spherical growth of the primary $\alpha-\mathrm{Al}$ grains is $23.4 \mu \mathrm{m}$. In fact, the growth rate is smaller than $3.9 \mu \mathrm{m} / \mathrm{s}$ because the solidification in the shot sleeve is similar to gravity die casting with relatively lower cooling rates. Therefore, the resultant spherical growth of the primary $\alpha$-Al grains formed in the shot sleeve is less than $23.4 \mu \mathrm{m}$. However, the measured size of the primary $\alpha$-Al phase is $43 \mu \mathrm{m}$, which is much larger than the critical size predicted by the Mullins-Sekerka theory. Consequently, the grains will lose their stability for spherical growth and form a dendritic morphology. 


\section{Conclusion}

In the high pressure die casting of AlMgSiMn alloys, solidification includes two stages. The primary $\alpha$-Al phase formed in the shot sleeve is characterized by the dendrites and fragmented dendrites with the size range from 15 to $100 \mu \mathrm{m}$ and an average of $43 \mu \mathrm{m}$. The primary $\alpha$-Al phase formed in the die cavity is characterized by fine globular grains with an average of $7.5 \mu \mathrm{m}$ in size. Solidification inside the die cavity is also responsible for the formation of the lamellar $\mathrm{Al}-\mathrm{Mg}_{2} \mathrm{Si}$ eutectic and the Fe-rich intermetallics. The size of the eutectic cells is about $10 \mu \mathrm{m}$, in which the lamellar $\alpha$-Al phase is $0.41 \mu \mathrm{m}$ in thickness. The intermetallic compounds exhibit a compact morphology with a size smaller than $2 \mu \mathrm{m}$ and are located at the boundaries between the primary $\alpha$ $\mathrm{Al}$ grains or between eutectic cells and the primary $\alpha$-Al grains.

The stability criterion developed by Mullins and Sekerka for spherical growth can be used to provide a reasonable explanation for the difference in morphology of the primary $\alpha$-Al phase solidified in the shot sleeve and in the die cavity. The solidification of the $\alpha$-Al phase inside the die cavity has completed before the spherical grains begin to lose their stability, but the grains in the shot sleeve exceed the limit of spherical growth and, therefore, exhibit a dendritic morphology.

\section{References}

[1] E. J. Vinarcik, High Integrity Die Casting Processes, John Wiley \& Sons, New York, 2003.

[2] H. L. MacLean, L. B. Lave, Progress in Energy and Combustion Science 29 (20031) 1-69.

[3] W.S. Miller, L. Zhuang, J. Bottema, A.J. Wittebrood, P. DeSmet, A. Haszler, A. Vieregge, Mater. Sci. Eng. A 280 (2000)37-49.

[4] R.J. Orsato, P. Wells, J. Cleaner Production 15(2007) 994-1006.

[5] D. Carle, G. Blount, Materials \& Design 20 (1999) 267-272.

[6] European Aluminium Association, Aluminium in cars. European Aluminium Association, 2008

[7] S. Ji, D. Watson, Z. Fan, M. White, Mater. Sci. Eng. A 556(2012) 824 -33.

[8] S. Ji, W. Yang, F. Gao, D. Watson, Z. Fan, Mater. Sci. Eng. A 564 (2013) 130 -39.

[9] D. Apelian, Aluminium Cast Alloys, Enabling Tools for Improved Performance. North American Die Casting Association, Wheeling, Illinois, USA, 2009, pp.1-68.

[10] P. Krug, H. Koch, R. Klos, Magsimal-25 - A new High-Ductility Die Casting Alloy for Structural Parts in Automotive Industry, www.dgm.de/download/tg/523/523_0784.pdf.

[11] A.K. Dahle, D. H. StJohn, Acta Mater. 47(1999)31-41.

[12] A. Hamasaiid, M.S. Dargusch, C.J. Davidson, S. Tovar, T. Loulou, F. Rezai-Aria, G. Dour, Metall. Mater. Trans. A 38(2007) 1303-15.

[13] W.W. Mullins, R.F. Sekerka, J. Appl. Phys. 34(1963)323-29.

[14] E.A. Brandes, G.B. Brook, Smithells metals reference book. 7th ed. Oxford: Butterworth; 1992.

[15] A. L. Greer, A. M. Bunn, A. Tronche, P.V. Evans, D.J. Bristow, Acta Mater. 48(2000)2823-35.

[16] T. F. Bower, H. D. Brody, M.C. Flemings, Trans. AIME. 236 (1966) 624-33.

[17] M. H. Burden, J.D. Hunt, J. Cryst. Growth 22(1974)99-108.

[18] J. D. Hunt, S. Z. Lu, Metall. Mater. Trans. A 27(1996)611-23. 